\title{
Genetic diversity of group A rotavirus in acute gastroenteritis outpatients in Shanghai from 2017 to 2018
}

\author{
Xiaozhou Kuang ${ }^{1+}$, Xiaohuan Gong $^{1 \dagger}$, Xi Zhang $^{1}$, Hao Pan ${ }^{1 *}$ and Zheng Teng ${ }^{2^{*}}$
}

\begin{abstract}
Background: Group A Rotavirus (RVA), despite being an important pathogen in hospitalized children, is less studied in pediatric outpatients, and even rarely investigated in adults. This study aims to understand the genetic diversity of RVA in outpatients across all age groups in Shanghai, and thus providing a molecular basis for vaccine implementation and evaluation.

Methods: Stool samples were first screened by Real-time Reverse Transcription Polymerase Chain Reaction (rRTPCR). RVA genotyping was performed through the amplification of partial VP7 and VP4 gene. Strains of interest were further sequenced and analyzed using MEGA 6.0.

Results: Four thousand nine hundred one samples were collected, from which $7.61 \%$ (373 cases) were screened positive for RVA. RVA prevalence was higher in children (9.30\%) than in adults (7.21\%) $\left(x^{2}=4.72, P<0.05\right) .9 .38 \%$ RVA positive cases had taken antibiotics before hospital visit while $49.60 \%$ had been prescribed antibiotics afterwards. RVA displayed a strong seasonality in both adults and children with a shared commonality in genotype repertoire, where G9P[8] was the most prevalent strain (67.96\%) followed by G3P[8] (15.49\%) and G1P[8] (12.32\%). Meanwhile the first local case of fecal shedding of the G10P[15] vaccine strain was also discovered.

Conclusions: While the prevalence of rotavirus is highest during cold seasons, it is revealed for the first time that G9P[8] is the predominant genotype in both adults and pediatric outpatients. Clinically, higher occurrence of nausea or vomiting was observed in RVA positive cases. Antibiotic overuse was implicated in both non-clinical and clinical settings. The finding emphasizes the importance of RVA genotyping in surveillance as it provides the basis for new vaccine application as well as a baseline for future vaccine efficacy evaluation.
\end{abstract}

Keywords: Group A rotavirus, Acute gastroenteritis, Outpatients, Genotype, Antibiotics, Fecal shedding

\footnotetext{
* Correspondence: panhao@scdc.sh.cn; tengzheng@scdc.sh.cn

${ }^{+}$Xiaozhou Kuang and Xiaohuan Gong contributed equally to this work.

'Shanghai Municipal Center for Disease Control and Prevention, 1380

Zhongshan Road (west), Shanghai 200336, China

${ }^{2}$ Shanghai Institutes of Preventive Medicine, 1380 Zhongshan Road (west),

Shanghai 200336, China
}

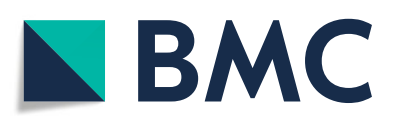

( The Author(s). 2020 Open Access This article is licensed under a Creative Commons Attribution 4.0 International License, which permits use, sharing, adaptation, distribution and reproduction in any medium or format, as long as you give appropriate credit to the original author(s) and the source, provide a link to the Creative Commons licence, and indicate if changes were made. The images or other third party material in this article are included in the article's Creative Commons licence, unless indicated otherwise in a credit line to the material. If material is not included in the article's Creative Commons licence and your intended use is not permitted by statutory regulation or exceeds the permitted use, you will need to obtain permission directly from the copyright holder. To view a copy of this licence, visit http://creativecommons.org/licenses/by/4.0/. The Creative Commons Public Domain Dedication waiver (http://creativecommons.org/publicdomain/zero/1.0/) applies to the data made available in this article, unless otherwise stated in a credit line to the data. 


\section{Background}

Rotavirus is an important pathogen in viral gastroenteritis, especially in children. According to $\mathrm{WHO}$, rotavirus still caused 215,000 estimated deaths in $<5$ years old children globally by 2013 despite various vaccination efforts [1]. In 2016, a global disease burden study covering 195 countries has also reported that rotavirus was the leading etiology for diarrhea mortality among children under 5 years and among all ages [2]. In China, rotavirus caused around $40 \%$ and $30 \%$ of diarrhea-related hospitalizations and outpatient visits, respectively, among children aged $<5$ years [3].

Among three major rotavirus groups that can infect human and animals (group A, B, C), group A rotavirus (RVA) is the most important group in terms of epidemiological and clinical impact in human population [4]. Our local previous study from 2012 to 2016 has also shown that RVA accounted for $97.3 \%$ of all rotavirus infections in adult acute diarrhea outpatients [5]. Moreover, of all viral pathogens that cause acute diarrhea, only RVA is preventable through vaccination.

RVA is classified by a binary classification system based on immunological reactions and the structure of two most external proteins VP7 (or G genotype) and VP4 protein genes (or P genotype), which binds to their neutralizing antibodies independently [4]. Up to now, at least $27 \mathrm{G}$ genotypes and $37 \mathrm{P}$ genotypes of RVA have been reported in humans and animals [4]. The predominant RVA genotype circulating in China in recent years is G9P[8] [6], which is different from the prevalent genotypes such as G3P[8] and G1P[8] in the neighboring countries in South East Asia [7]. In Shanghai, RVA genotype distribution has only been investigated in limited sentinel hospitals, involving $<5$ yrs. inpatients. The predominant genotype in this population was G9P [8] [8]. However, RVA genotype diversity in outpatients involving all age groups remains to be discerned. Therefore, it is the very first time in local history that RVA profiles in both pediatric and adults outpatients involving large scale surveillance programme were ever investigated.

Regarding RVA related disease prevention In China, the Lanzhou lamb rotavirus (LLR) vaccine, despite not being included in the national mandatory vaccination programme, was the only available option in the last two decades until very recently. At the end of
2018, RotaTeq vaccine has been launched (though neither was it on the mandatory vaccine list) with a more promising efficacy by its decade long use around the world [9].

This study aims to gain insight into the genetic diversity of RVA in both children and adults in providing the basis for measuring vaccine efficacy in the near future.

\section{Methods}

Case definition, sentinel hospital recruitment, sampling method, stool sample process and RNA extraction

This study was conducted as one of the major parts of the Comprehensive Surveillance Programme of Diarrheal Diseases in Shanghai. The case definition, as well as procedures such as sentinel hospital recruitment, sampling method, stool sample process and RNA extraction was outlined in previous studies [10,11].

\section{Real-time reverse transcription polymerase chain reaction (rRT-PCR) screening}

All specimens were double screened for RVA by rRTPCR using commercially available kits (Shanghai Zhijiang Biotechnology Co. Ltd. (a.k.a. Liferiver Bio-Tech), and Jiangsu Shuoshi Biotechnology Co., Ltd. (a.k.a. BioPerfectus Technologies)) according to the manufacturer's instructions.

\section{RVA genotyping}

For samples that were positive in both rRT-PCR kits, VP4 and VP7 regions were amplified by nested PCR using reagents and primers detailed in literature [12-15]. Similarly, genotypes were determined according to their respective product size by capillary gel electrophoresis described previously [12-15]. Strains of interest were further sequenced, and the resultant sequences spliced using the same methods from earlier studies $[11,16]$. These sequences were then classified by RVA online genotyping tool (http:// rotac.regatools.be, RotaC, Leuven, Belgium) [17]. Sequences representative of the main variants of strains which are of focus in this study were deposited in GenBank (accession numbers MN816183-202; MN833128-138).

\section{Phylogenetic analysis}

For strains of interest, phylogenetic trees were constructed in MEGA version 6.0 by applying the maximum

Table 1 RVA positive rates by rRT-PCR screening in adult and pediatric outpatients in 2017-2018

\begin{tabular}{|c|c|c|c|c|c|c|c|c|}
\hline \multirow[b]{2}{*}{ Year } & \multicolumn{4}{|l|}{ Adults } & \multicolumn{4}{|l|}{ Children } \\
\hline & No. of cases & No. of RVA POS & POS rate $(\%)$ & $X^{2}$ (P-value) & No. of cases & No. of RVA POS & POS rate (\%) & $X^{2}$ (P-value) \\
\hline 2017 & 2115 & 155 & 7.33 & $0.09(0.76)$ & 496 & 39 & 7.86 & $2.60(0.11)$ \\
\hline 2018 & 1851 & 131 & 7.08 & & 439 & 48 & 10.93 & \\
\hline Total & 3966 & 286 & 7.21 & & 935 & 87 & 9.30 & \\
\hline
\end{tabular}


Table 2 RVA positive rates by rRT-PCR screening in male and female outpatients

\begin{tabular}{|c|c|c|c|c|c|c|c|c|}
\hline \multirow[b]{2}{*}{ Gender } & \multicolumn{4}{|l|}{ Adults } & \multicolumn{4}{|l|}{ Children } \\
\hline & No. cases & No. RVA POS & POS rate (\%) & $\overline{X^{2} \text { (P-value) }}$ & No. cases & No. RVA POS & POS rate (\%) & $x^{2}$ (P-value) \\
\hline Male & 2059 & 149 & 7.24 & $0.01(0.95)$ & 507 & 39 & 7.69 & $3.41(0.06)$ \\
\hline Female & 1907 & 137 & 7.18 & & 428 & 48 & 11.21 & \\
\hline Total & 3966 & 286 & 7.21 & & 935 & 87 & 9.30 & \\
\hline
\end{tabular}

likelihood method, using the substitution models suggested by the MEGA6 model test for each tree [18]. Tree robustness was determined by bootstrapping using 1000 pseudo replicates [19].

\section{Statistical analysis}

All calculations were conducted using Microsoft Excel 2010 and SPSS software v16.0 (IBM, USA), where Cochren Mantel-Haenszel Chi square test and the Fisher's exact with two-tailed method were used to determine statistical significance with $P<0.05$.

\section{Results}

\section{Overall demographic analysis on RVA positive detection} rate

From January 2017 to December 2018, a total of 4901 stool samples with epidemiological information were collected from diarrhea outpatients, including 2611 samples from 2017, and 2290 samples from 2018. A total of 373 samples $(7.61 \%)$ were positive for RVA by rRT-PCR (Table 1). The overall RVA positive rate in children was significantly higher than that in adults $\left(X^{2}=4.72, P<\right.$ 0.05).

Within the same population, no significant difference in RVA prevalence was observed between male and female (Table 2).

In adults, the median age in RVA positive cases (46 yrs.) and RVA negative cases ( 42 yrs.) was not significantly different (Wilcoxon signed-rank test, $P=0.10$ ). However, in children, the median age (18 mth.) in RVA positive cases was higher than that in RVA negative cases (15 mth.) (Wilcoxon signed-rank test, $P<0.05$ ).

Disparities in RVA prevalence among various age groups were perceived in both adults and children, with the highest prevalence in $45-54$ yrs. and 3-5 yrs. group respectively (Tables 3 and 4).

Table 3 RVA positive rate in different age groups in adults

\begin{tabular}{lllll}
\hline Age group (yr.) & No. cases & No. RVA POS & RVA POS rate $(\%)$ & $x^{2}$ (P-value) \\
\hline $15-34$ & 1496 & 98 & 6.55 & 2.55 \\
$35-44$ & 589 & 36 & 6.11 & $(<0.05)$ \\
$45-54$ & 493 & 53 & 10.75 & \\
$55-64$ & 733 & 57 & 7.78 & \\
$\geq 65$ & 626 & 39 & 6.23 & \\
Total & 3937 & 283 & 7.19 & \\
\hline
\end{tabular}

Significant difference in RVA positive rate was observed among different residency groups in pediatric cases, with the highest in local migrants. However, such difference in adult cases was insignificant (Table 5).

Further analysis in pediatric cases showed insignificant differences in RVA prevalence among children living at home, cared in kindergarten, and studying in elementary and middle school $\left(\chi^{2}=2.23, P=0.33\right)$ (Table 6).

\section{Clinical symptoms, epidemiological history and antibiotic administration in RVA cases}

Cases positive for RVA and other viral pathogens generally had higher occurrence of nausea and vomiting as the first symptoms accompanying diarrhea in both adults and children (Table 7).

On the contrary, fever occurred most frequently in cases infected only by bacteria, and occurred less so in RVA positive cases and cases with other types of viral infection (Table 8).

Similarly, the occurrence of abdominal distention and pain is lower in RVA positive cases than that in cases infected with other viruses and bacteria; it was even lower than cases with unknown causes (Tables 9 and 10).

When investigating the epidemiological history, it was found that in adult RVA positive cases, more patients recalled the intake of some suspicious food, compared to other cases with a different infection status. However, such pattern was not observed in children (Table 11).

On the other hand, no significant difference in the rate of pet contact prior to the onset was observed among different groups with difference infection status (Table 12).

Interestingly, in cases infected by RVA, the rate of selfadministration of antibiotics before hospital visit was significantly higher in adults than that in children. Similarly, the same pattern was observed in the rate of antibiotic treatment after the hospital visit (Table 13).

Table 4 RVA positive rate in different age groups in children

\begin{tabular}{lllll}
\hline Age group (yr.) & No. cases & No. RVA POS & RVA POS rate (\%) & $x^{2}$ (P-value) \\
\hline $0-6 \mathrm{~m}$ & 180 & 11 & 6.11 & 9.11 \\
$7 \mathrm{~m}-36 \mathrm{~m}$ & 596 & 58 & 9.73 & $(<0.05)$ \\
$3-5 \mathrm{yr}$ & 102 & 16 & 15.69 & \\
6-14 yr & 53 & 2 & 3.77 & \\
Total & 931 & 87 & 9.34 & \\
\hline
\end{tabular}


Table 5 RVA positive rate in different residency groups

\begin{tabular}{|c|c|c|c|c|c|c|c|c|}
\hline \multirow[b]{2}{*}{ Residency group } & \multicolumn{4}{|l|}{ Adults } & \multicolumn{4}{|l|}{ Children } \\
\hline & no. adults & no. RVA pos. & RVA pos. Rate (\%) & $X^{2}$ (P-value) & no. children & no. RVA pos. & RVA pos. Rate (\%) & $\overline{X^{2}(P \text {-value })}$ \\
\hline Local residence & 3304 & 244 & 7.38 & $1.86(0.40)$ & 698 & 55 & 7.88 & $6.70(<0.05)$ \\
\hline Local migrant ${ }^{a}$ & 407 & 29 & 7.13 & & 151 & 21 & 13.91 & \\
\hline Floating population & 255 & 13 & 5.10 & & 86 & 11 & 12.79 & \\
\hline Total & 3966 & 286 & 7.21 & & 935 & 87 & 9.30 & \\
\hline
\end{tabular}

aLocal migrant is defined as people who have resided in Shanghai for more than 6 months but have not yet obtained permanent residency

\section{Seasonal variation in RVA detection rate}

RVA positive detection rate peaked in every winter and reached its highest at 35.53\% in Jan 2018 (Fig. 1). On the other hand, RVA positive rate dropped gradually with the rise of atmospheric temperature, and plummeted in summers as shown in Fig. 1.

\section{RVA genotype diversity}

Of 373 RVA positive samples, 284 samples (76.14\%) were genotyped successfully. Table 14 shows the percentage composition of various RVA genotypes.

Monthly composition of different RVA genotypes showed that genotype G9P[8] was the predominant genotype in both adults and children (Fig. 2a, b). Less dominant genotypes such as G3P[8] and G1P[8] were more abundant in seasons with low RVA circulation.

Generally speaking, there was a more diverse genotype profile of RVA in adults than that in children, with the highest diversity shown in $15-34$ yrs. and $\geq 65$ yrs. age group (Fig. 3). Additionally, G9P[8] was detected across all age group.

\section{Investigation of one G10P[15] case}

Genotype G10P[15] was identified in one child with RVA infection. Further investigation of this case revealed the patient to be a migrant girl reaching 5 month of age upon the initial onset of diarrhea. Unfortunately, due to the absence of hospital visit when first symptoms were developed, the original cause of her diarrhea was unknown. Six days after the disease onset, her parents felt the child was well enough to take the first dose of RVA LLR vaccine. However, the mild diarrhea still persisted, which brought about the child's hospital visit 8 days after vaccine intake. And this is the point where the stool samples were collected and tested. It should be noted that no antibiotics were prescribed or administered prior to or after the hospital visit; and no gastric symptoms were ever present before the development of this ongoing gastroenteritis. Apart from watery diarrhea, no other symptoms were accompanied throughout clinical manifestation.

In this case, partial VP7 and VP4 gene were sequenced and its lineage was subsequently analyzed. It was found that for both of these above regions, it shared >99\% identity with LLR vaccine (Fig. 4a, b).

\section{Discussion}

Because of the conventional belief that RVA was the leading pathogen in pediatric acute gastroenteritis, its prevalence in adults was often overlooked. In our study, it was shown that RVA prevalence in adult outpatients was as high as $7.21 \%$, albeit being lower than $9.30 \%$ in children as expected. Furthermore its prevalence in adults was similar to $7.90 \%$ found during 2012-2016 in Shanghai [5]. However the local RVA positive rate in pediatric outpatients was lower than that in pediatric inpatients (13.95\%) from our previous study [8], this is probably because RVA is more likely to cause severe cases that result in hospitalization in children [20].

Compared with other regions across China, our rates were lower than the average RVA prevalence (11.2\%) from pediatric outpatients in high-income regions, and even much lower than that in low-income regions (40.7\%) [6]. It was also much lower than that in countries such as India (36.21\% in pediatric cases, and $20.73 \%$ in adult cases) [21], Middle East regions and North Africa (19-40\%) [22]. On the contrary, the local RVA rate was higher than the median annual rate $(6.1 \%)$ reported during post vaccine period (2007-2018) in US from CDC's National Respiratory and Enteric Viruses Surveillance System [23]. These differences might be associated both with the socioeconomic status and the vaccine coverage in the particular region. It should also be noted

Table 6 RVA positive rate in children with different childcare types

\begin{tabular}{llll}
\hline Types of childcare facilities & no. cases & no. RVA pos. & RVA pos. Rate (\%) \\
\hline living at home & 783 & 74 & 9.45 \\
kindergartens & 83 & 10 & 12.05 \\
elementary and middle school & 48 & 2 & 4.17 \\
\hline
\end{tabular}


Table 7 Occurrence of nausea and vomiting as first symptoms that accompanied diarrhea in cases with different infection status

\begin{tabular}{|c|c|c|c|c|c|c|c|c|}
\hline \multirow[b]{2}{*}{ Cases with different infection status } & \multicolumn{4}{|l|}{ Adults } & \multicolumn{4}{|l|}{ Children } \\
\hline & No. cases & No. vomit accompanied & Rate $(\%)$ & $X^{2}$ (P-value) & No. cases & $\begin{array}{l}\text { No. vomit } \\
\text { accompanied }\end{array}$ & Rate (\%) & $\overline{X^{2} \text { ( } P \text {-value) }}$ \\
\hline RVA POS & 286 & 16 & 5.59 & $9.07(<0.05)$ & 87 & 5 & 5.75 & $(<0.05)^{*}$ \\
\hline POS for other virus & 869 & 59 & 6.79 & & 188 & 8 & 4.26 & \\
\hline Bacteria POS \& virus NEG & 752 & 27 & 3.59 & & 160 & 0 & 0.00 & \\
\hline Unknown cause & 2059 & 100 & 4.86 & & 500 & 6 & 1.20 & \\
\hline
\end{tabular}

*Fisher's exact

that before the end of 2018, only LLR vaccine, which contained a single genotype G10P[15] originated from goat, was licensed in China; while multiple multi-valent vaccines with higher efficacy were used in other countries [24].

Interestingly, in recent years in Shanghai, RVA ranked second in causing acute diarrhea in both outpatients and inpatients studies, and in both adults and children, the first being norovirus $[5,8,11]$. Our finding was consistent with the phenomenon observed in US and other developed countries, i.e. the rotavirus vaccine might contribute to the decline of RVA and the rising of other viral pathogens such as norovirus [25]. Moreover, studies conducted in Southern China has confirmed a negative correlation between RVA prevalence and vaccination coverage [26].

Children infected by RVA tend to be older than those not infected by RVA. This was as expected largely due to maternal antibody protection in younger infants [27], RVA vaccination coverage and in some small part, the intake of human milk and dairy fractions, which contained lactoferrin in possessing some antirotaviral activity [28]. Studies in various provinces in China had discovered that RVA prevalence was highest in 1-2 yrs. old population [6]. However, in our study, RVA prevalence was highest in 3-5yrs. old children, followed by 7-36 mth old children. This discrepancy might be due to a disproportionally smaller sample size in $3-5 \mathrm{yrs}$. age group in our study. It is believed that while children older than 3 years were often already infected by RVA, and thus causing the elevation of their antibody level in preventing further reinfection [29].

In terms of symptom, higher occurrence of nausea and vomiting, together with fewer occurrences of fever and abdominal discomfort was observed in RVA positive cases, compared with cases infected by bacteria. These milder clinical manifestation in viral diarrhea was consistent with previous findings [5]. It is plausible that specific molecular mechanism of viral infection in gastrointestinal system is one of the contributing factors. For instance, rotaviruses can cause acute severe diarrhea in the absence of substantial intestinal inflammation predominantly due to its ability to inhibit different types of interferons, and thus restricting antiviral and inflammatory functions [30]. As to why suspicious food intake was positively associated with RVA positive adults but not in children, it was probably caused by recall bias in children, whose food history was often answered by their parents, who were quite often reluctant to admit giving child the wrong food. Unfortunately, not all cases could recall the type of food they have taken, and not all mode of transmission were fully explored in the surveillance; more researches need to be conducted to fully confirm the finding.

Nearly $10 \%$ of RVA positive cases took antibiotics even before their hospital visit; while around $50 \%$ of RVA positive cases were prescribed with antibiotics after their hospital visit. As all of these recruited cases showed only mild symptoms and didn't require hospitalization, over self-administration and over prescription of antibiotics were implicated in current practice, particularly so in adults. Since overuse of antibiotics is one of the leading causes of antibiotic resistance, and can also cause allergy and adverse effects [31]; results found in this study could offer molecular diagnostic reference for general practitioner in treating acute diarrhea with more discretion, as well as in educational campaign on how to prevent antibiotic abuse in local residents.

Table $\mathbf{8}$ Occurrence of fever as one of the first symptoms in cases with different infection status

\begin{tabular}{lllll}
\hline Cases with different infection status & no. cases & no. cases w/ fever & Rate $(\%)$ & 16.62 \\
\hline RVA POS & 373 & 62 & 1 -value $)$ \\
POS for other virus & 1057 & 120 & 11.35 & $(<0.05)$ \\
Bacteria POS \& virus NEG & 912 & 194 & 21.27 \\
Unknown cause & 2559 & 312 & 12.19 \\
\hline
\end{tabular}


Table 9 Occurrence of abdominal distention as one of the first symptoms in cases with different infection status

\begin{tabular}{lllll}
\hline $\begin{array}{l}\text { Cases with different } \\
\text { infection status }\end{array}$ & no. cases & $\begin{array}{l}\text { no. cases } \\
\text { W/abdominal } \\
\text { distension }\end{array}$ & Rate (\%) & $X^{2}(P$-value $)$ \\
\hline RVA POS & 373 & 35 & 9.38 & 11.35 \\
POS for other virus & 1057 & 149 & 14.10 & $(<0.05)$ \\
Bacteria POS \& virus NEG & 912 & 117 & 12.83 \\
Unknown cause & 2559 & 274 & 10.71 \\
\hline
\end{tabular}

Table 10 Occurrence of abdominal pain as one of the first symptoms in cases with different infection status

\begin{tabular}{lllll}
\hline $\begin{array}{l}\text { Cases with different } \\
\text { infection status }\end{array}$ & no. cases & $\begin{array}{l}\text { no. cases w/ abdominal } \\
\text { pain }\end{array}$ & Rate $(\%)$ & $X^{2}(P$-value $)$ \\
\hline RVA POS & 373 & 124 & 33.24 & 92.08 \\
POS for other virus & 1057 & 389 & 36.80 & $(<0.05)$ \\
Bacteria POS \& virus NEG & 912 & 507 & 55.59 \\
Unknown cause & 2559 & 1179 & 46.07 \\
\hline
\end{tabular}

Table 11 Percentage of suspicious food intake prior to the onset of diarrhea in cases with different infection status

\begin{tabular}{|c|c|c|c|c|c|c|c|c|}
\hline \multirow[b]{2}{*}{ Cases with different infection status } & \multicolumn{4}{|l|}{ Adults } & \multicolumn{4}{|l|}{ Children } \\
\hline & No. cases & $\begin{array}{l}\text { No. cases } \\
\text { w/ suspicious } \\
\text { food intake }\end{array}$ & Rate(\%) & $\begin{array}{l}X^{2}(P- \\
\text { value })\end{array}$ & No. cases & $\begin{array}{l}\text { No. cases } \\
\text { W/ suspicious } \\
\text { food intake }\end{array}$ & Rate(\%) & $X^{2}$ (P-value) \\
\hline RVA POS & 286 & 198 & 69.23 & \multirow{4}{*}{$\begin{array}{l}9.80 \\
(<0.05)\end{array}$} & 87 & 3 & 3.45 & \multirow[t]{4}{*}{$2.42(0.49)$} \\
\hline Other virus POS & 869 & 523 & 60.18 & & 188 & 10 & 5.32 & \\
\hline Bacteria POS \& virus NEG & 752 & 450 & 59.84 & & 160 & 13 & 8.13 & \\
\hline Unknown cause & 2059 & 1230 & 59.74 & & 500 & 31 & 6.20 & \\
\hline
\end{tabular}

Table 12 Percentage of pet contact prior to the onset of diarrhea in cases with different infection status

\begin{tabular}{|c|c|c|c|c|c|c|c|c|}
\hline \multirow[b]{2}{*}{$\begin{array}{l}\text { Cases with different infection } \\
\text { status }\end{array}$} & \multicolumn{4}{|c|}{ Adults } & \multicolumn{4}{|c|}{ Children } \\
\hline & $\begin{array}{l}\text { No. } \\
\text { cases }\end{array}$ & $\begin{array}{l}\text { No. cases w/ pet } \\
\text { contact }\end{array}$ & Rate(\%) & $\begin{array}{l}X^{2}(P- \\
\text { value })\end{array}$ & $\begin{array}{l}\text { No. } \\
\text { cases }\end{array}$ & $\begin{array}{l}\text { No. cases w/ pet } \\
\text { contact }\end{array}$ & Rate(\%) & $\begin{array}{l}X^{2}(P- \\
\text { value })\end{array}$ \\
\hline RVA POS & 286 & 11 & 3.85 & $6.27(0.10)$ & 87 & 56 & 64.37 & $0.32(0.96)$ \\
\hline Other virus POS & 869 & 32 & 3.68 & & 188 & 123 & 65.43 & \\
\hline Bacteria POS \& virus NEG & 752 & 23 & 3.06 & & 160 & 106 & 66.25 & \\
\hline Unknown cause & 2059 & 103 & 5.00 & & 500 & 320 & 64.00 & \\
\hline
\end{tabular}

Table 13 RVA positive cases with antibiotic administration before and after hospital visit

\begin{tabular}{|c|c|c|c|c|c|c|c|}
\hline RVA POS cases & No. cases & No. cases w/ prior antibiotic intake & Rate(\%) & $x^{2}$ (P-value) & No. cases treated w/ antibiotics & Rate(\%) & $x^{2}$ (P-value) \\
\hline Adults & 286 & 32 & 11.19 & $4.70(<0.05)$ & 176 & 61.54 & $69.94(<0.05)$ \\
\hline Children & 87 & 3 & 3.45 & & 9 & 10.34 & \\
\hline Total & 373 & 35 & 9.38 & & 185 & 49.60 & \\
\hline
\end{tabular}




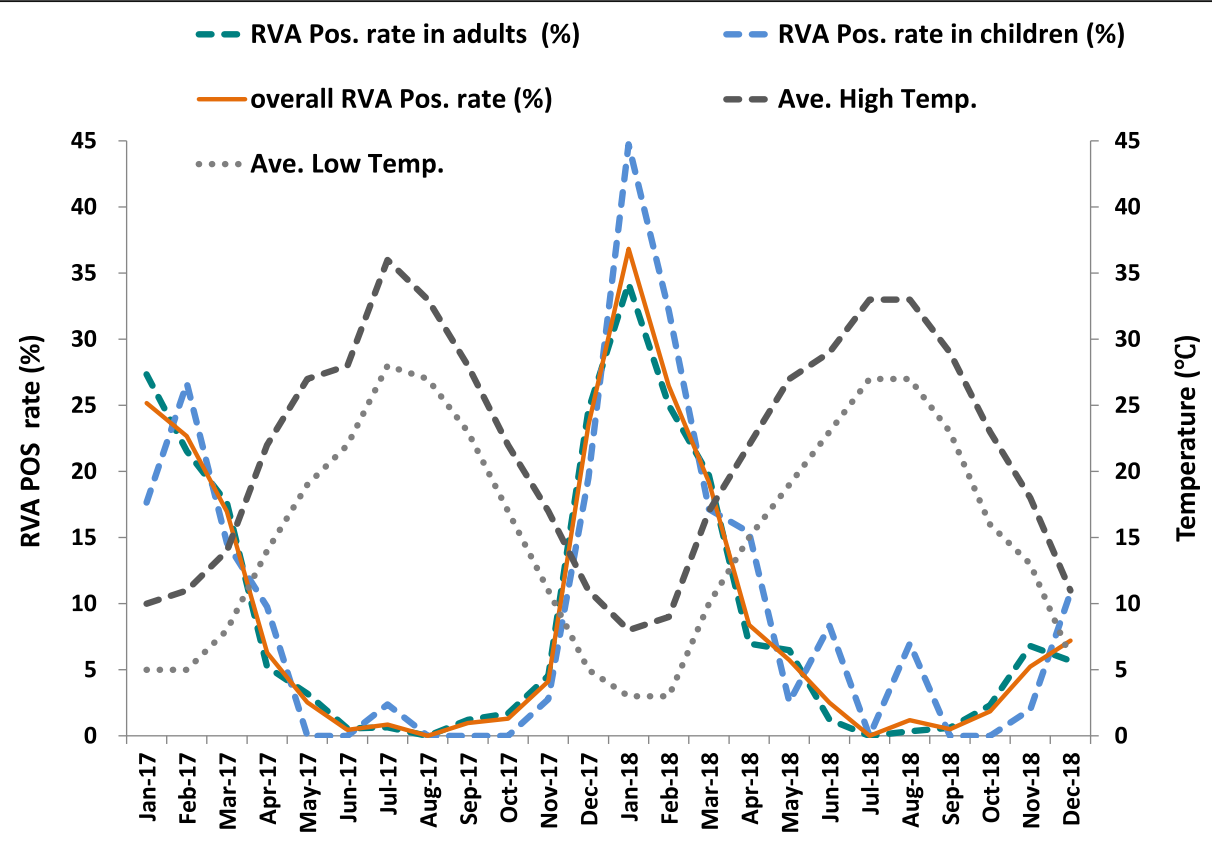

Fig. 1 Seasonal prevalence of RVA in both adult and pediatric outpatients

RVA displayed a strong seasonality in both adults and children. This was consistent with the finding in the neighboring city in Hangzhou, Zhejiang province, in which a negative correlation between temperature and rotavirus infection rate was established [32]. Similarly higher temperatures were also linked to fewer hospitalizations for rotavirus in both Shanghai and Hong Kong $[8,33]$. These phenomenon probably resulted from a more rapid loss of rotavirus infectivity at higher temperatures [34].

Regarding the genotype diversity, commonality in RVA genotype repertoire was shared between adults and children; though child-to-adult transmission was once proposed in adult rotavirus infection [35], more thorough investigation on the dynamic mode of transmission must be conducted before drawing any solid conclusion.
In both populations, G9P[8] was the most prevalent genotype, followed by G3P[8] and G2P[4]. Similar genotypes and their prevalence ranking pattern were observed in hospitalized children in Shanghai [8] as well as pediatric outpatients in Beijing [36]. It's worth noting that G9P [8] is also the most prevalent genotype found in sewage in eastern China [37], which probably served as an environmental reservoir for disease transmission. Since 2008, G9P [8] genotype had replaced its predecessor G3P[8] through genetic evolution in becoming the predominant strain circulating in China [36]. Interestingly, all circulating strains appeared to be a mismatch with G10P[15] identified in LLR vaccine [24]. Studies had revealed that LLR could only offer around 30\% protection against the circulating strains [26]. Furthermore, even the newly launched RotaTeq vaccine lacks a G9

Table 14 RVA genotype constitution

\begin{tabular}{|c|c|c|c|c|c|c|}
\hline RVA genotypes & No. adults & Percentage (\%) & No. children & Percentage (\%) & Total no. cases & Percentage (\%) \\
\hline G9P[8] & 143 & 65.30 & 50 & 76.92 & 193 & 67.96 \\
\hline G3P[8] & 33 & 15.07 & 11 & 16.92 & 44 & 15.49 \\
\hline G2P[4] & 32 & 14.61 & 3 & 4.62 & 35 & 12.32 \\
\hline G1P[8] & 8 & 3.65 & 0 & 0.00 & 8 & 2.82 \\
\hline G9P[4] & 2 & 0.91 & 0 & 0.00 & 2 & 0.70 \\
\hline G10P[15] & 0 & 0.00 & 1 & 1.54 & 1 & 0.35 \\
\hline G2P[4]+G9P[8] & 1 & 0.46 & 0 & 0.00 & 1 & 0.35 \\
\hline Total & 219 & 100.00 & 65 & 100.00 & 284 & 100.00 \\
\hline
\end{tabular}



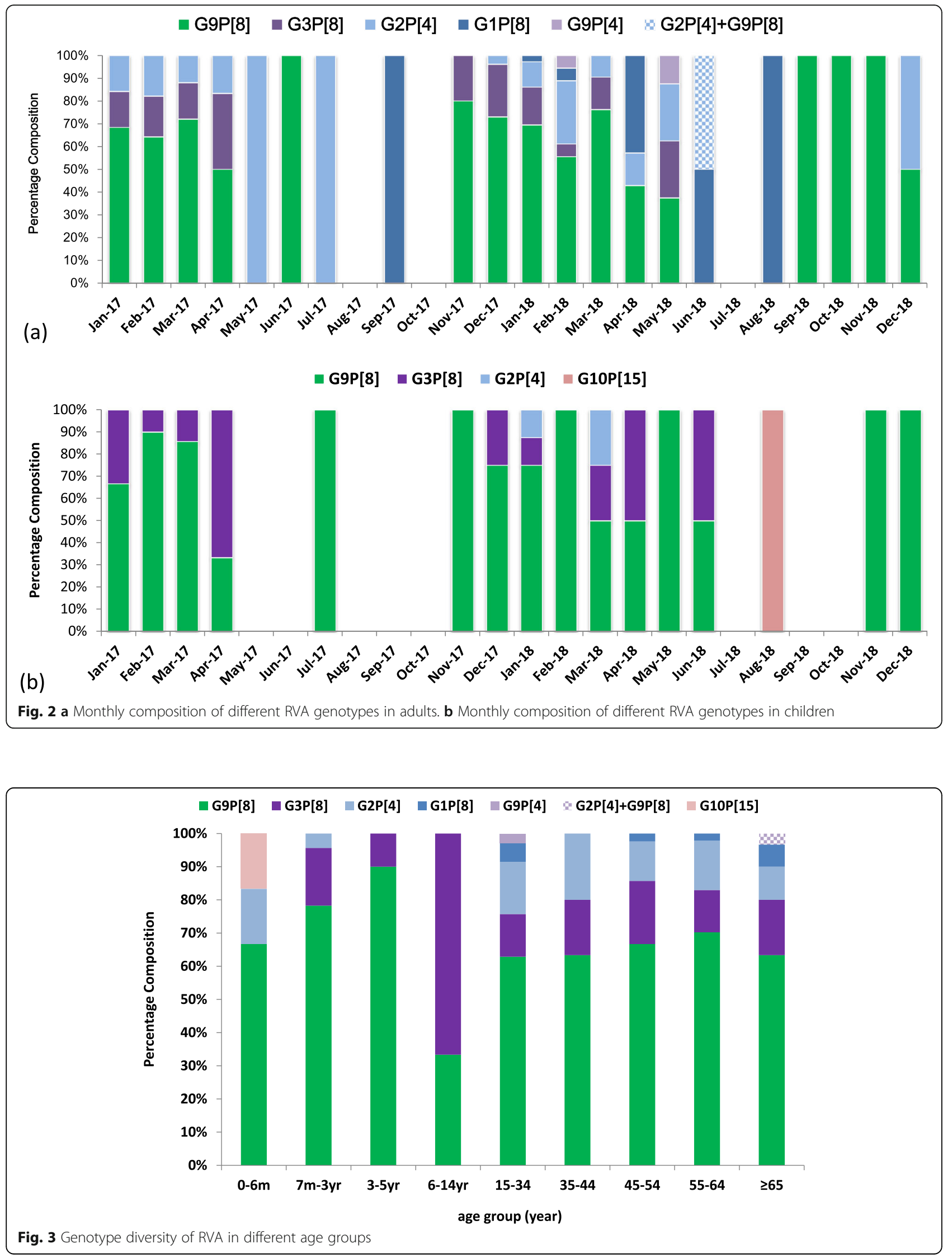


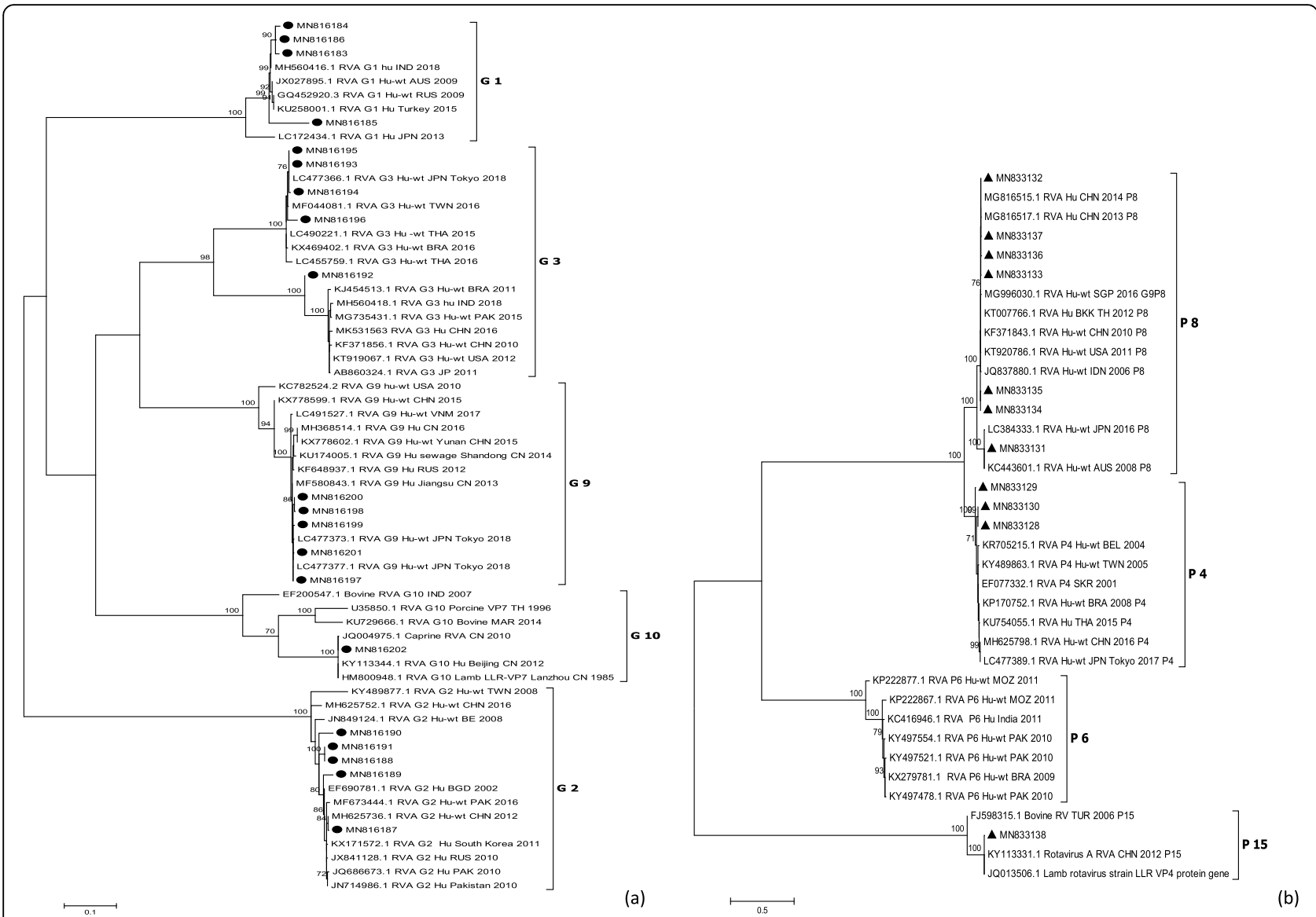

Fig. 4 Phylogenetic analysis of RVA (a) partial VP7 gene (863 bp) with strains identified in this study shown in black solid circles (b) partial VP4 gene $(663 \mathrm{bp})$ with strains identified in this study shown in black solid triangles. The trees were constructed in Mega 6.0 using the maximum likelyhood method with T92 + G + I model for VP7 tree and TN93 + G + I model for VP4 tree. The bootstrap values generated from 1000 replicates are shown at nodes, and only bootstrap values $>70 \%$ are shown

genotype in spite of offering a better vaccine efficacy than LLR [9], hence there is still room for optimization in vaccine application.

With one curious case of G10P[15] strain detected in one young infant, such shedding of LLR vaccine was the first reported case in Shanghai. However, similar shedding of vaccine strain was also found in RVA-vaccinated children in Beijing, where fecal shedding occurred as early as postvaccination day 2 and as late as post-vaccination day 13 and peaked on post-vaccination day 5-10 [38]. In our case, fecal shedding was detected on day 8 after first dose of vaccine, which fell into the range with previous finding [38]. Since LLR was still a live attenuated strain, it has the potential to replicate in human intestine notwithstanding its animal origin [39]. Nevertheless, further information as well as more in-depth research on molecular level was required to determine whether the prolonged mild diarrhea was indeed caused by vaccination.

\section{Conclusion}

RVA displayed a strong seasonality in Shanghai from 2017 to 2018. RVA prevalence was higher in children than in adult outpatients. Clinically, RVA positive cases tend to suffer from milder abdominal discomfort despite having higher occurrence of nausea and vomiting. Furthermore, over self-administration and prescription of antibiotics was indicated in our study. On a molecular level, G9P[8] was the predominant genotype in both children and adults. Moreover, molecular genotyping also facilitated the identification of first case of fecal shedding of LLR vaccine. Overall, it is paramount to continue RVA genotyping through routine surveillance; as it provides an insight into the genetic diversity of RVA both as a baseline and changing trends after the implementation of vaccines. Data obtained from such surveillance system could also be used to evaluate vaccine efficacy in the near future. 


\section{Abbreviations}

RVA: group A rotavirus; rRT-PCR: Real-time Reverse Transcription -Polymerase Chain Reaction

\section{Acknowledgements}

We would like to thank 27 sentinel hospitals and 16 district labs for their continuous contribution to Shanghai Comprehensive Gastroenteritis Surveillance Programme. We are also indebted to our colleague Mr. Jiechen Liu in helping us to find vaccination record for our special case with the fecal shedding of LLR vaccine strain.

\section{Consent for publications}

Not applicable.

\section{Authors' contributions}

XK performed the experiments, conducted the analysis, and drafted and revised the manuscript. XG conducted epidemiology related statistical analysis and provide suggestions in the refinement of manuscript. $X Z$ helped in revising the manuscript. ZT and HP both designed and supervised the study and commented on the manuscript. All authors have ensured the accuracy and integrity of this article. The authors have read and approved the final manuscript.

\section{Funding}

This work was supported by National "Thirteenth Five-Year" Program of Key Research and Development for Infectious Disease Prevention (2017ZX10103009-003). The funders had no role in study design, data collection and analysis, decision to publish, or preparation of the manuscript.

\section{Availability of data and materials}

Sequences presented in the result section were deposited in GenBank (accession numbers MN816183-202; MN833128-138). All data involved in this study is available upon reasonable request made to the corresponding authors.

GenBank MN816183-MN816202, MN833128-MN833138.

MN816183:https:/www.ncbi.n/m.nih.gov/nuccore/MN816183.1?report=GenBank MN816184:https://www.ncbi.nlm.nih.gov/nuccore/MN816184.1?report=GenBank MN816185:https://www.ncbi.nlm.nih.gov/nuccore/MN816185.1?report=GenBank MN816186:https://www.ncbi.nlm.nih.gov/nuccore/MN816186.1?report=GenBank MN816187:https:/www.ncbi.nlm.nih.gov/nuccore/MN816187.1?report=GenBank MN816188:https://www.ncbi.nlm.nih.gov/nuccore/MN816188.1?report=GenBank MN816189:https:/www.ncbi.n/m.nih.gov/nuccore/MN816189.1?report=GenBank MN816190:https:/www.ncbi.nlm.nih.gov/nuccore/MN816190.1?report=GenBank MN816191:https:/www.ncbi.n/m.nih.gov/nuccore/MN816191.1?report=GenBank MN816192:https:/www.ncbi.n/m.nih.gov/nuccore/MN816192.1?report=GenBank MN816193:https:/www.ncbi.n/m.nih.gov/nuccore/MN816193.1?report=GenBank MN816194:https://www.ncbi.nlm.nih.gov/nuccore/MN816194.1?report=GenBank MN816195:https:/www.ncbi.n/m.nih.gov/nuccore/MN816195.1?report=GenBank MN816196:https://www.ncbi.nlm.nih.gov/nuccore/MN816196.1?report=GenBank MN816197:https://www.ncbi.nlm.nih.gov/nuccore/MN816197.1?report=GenBank MN816198:https://www.ncbi.nlm.nih.gov/nuccore/MN816198.1?report=GenBank MN816199:https://www.ncbi.nlm.nih.gov/nuccore/MN816199.1?report=GenBank MN816200:https:/www.ncbi.n/m.nih.gov/nuccore/MN816200.1?report=GenBank MN816201:https://www.ncbi.nlm.nih.gov/nuccore/MN816201.1? report=GenBank MN816202:https:/www.ncbi.n/m.nih.gov/nuccore/MN816202.1?report=GenBank MN833128:https:/www.ncbi.n/m.nih.gov/nuccore/MN833128.1?report=GenBank MN833129:https:/www.ncbi.n/m.nih.gov/nuccore/MN833129.1?report=GenBank MN833130:https://www.ncbi.nlm.nih.gov/nuccore/MN833130.1?report=GenBank MN833131:https:/www.ncbi.nlm.nih.gov/nuccore/MN833131.1?report=GenBank MN833132:https://www.ncbi.nlm.nih.gov/nuccore/MN833132.1?report=GenBank MN833133:https://www.ncbi.nlm.nih.gov/nuccore/MN833133.1?report=GenBank MN833134:https://www.ncbi.nlm.nih.gov/nuccore/MN833134.1?report=GenBank MN833135:https://www.ncbi.nlm.nih.gov/nuccore/MN833135.1?report=GenBank MN833136:https:/www.ncbi.n/m.nih.gov/nuccore/MN833136.1?report=GenBank MN833137:https://www.ncbi.nlm.nih.gov/nuccore/MN833137.1?report=GenBank MN833138:https:/www.ncbi.nlm.nih.gov/nuccore/MN833138.1?report=GenBank

\section{Ethics approval and consent to participate}

The study protocol was approved by the Ethics Review Board of Shanghai Municipal Center for Disease Control and Prevention, China. Tests were performed on existing stool samples, which were collected as part of the routine medical tests prescribed by the clinicians; and no additional tests involving any invasive procedures, were performed on patients. Sample collection was approved by participants with prior verbal consent in minimizing the waiting line and optimizing patient experience in clinical settings. Although the option of written approval was also provided, all participants chose to give their verbal consent due to convenience. These procedures were approved by the above ethics committee.

\section{Competing interests}

The authors declare that they have no Competing interests.

\section{Received: 29 February 2020 Accepted: 20 July 2020}

Published online: 12 August 2020

\section{References}

1. Tate JE, Burton AH, Boschi-Pinto C, et al. Global, regional, and National Estimates of rotavirus mortality in children $<5$ years of age, 2000-2013. Clin Infect Dis. 2016;62(Suppl 2):S96-s105. https://doi.org/10.1093/cid/civ1013.

2. Estimates of the global, regional, and national morbidity, mortality, and aetiologies of diarrhoea in 195 countries: a systematic analysis for the global burden of disease study. Lancet Infect Dis, 2018. 2016;18(11):1211-28. https://doi.org/10.1016/s1473-3099(18)30362-1.

3. Wu D, Yen C, Yin ZD, et al. The public health burden of rotavirus disease in children younger than five years and considerations for rotavirus vaccine introduction in China. Pediatr Infect Dis J. 2016;35(12):e392-8. https://doi. org/10.1097/inf.0000000000001327.

4. Matthijnssens J, Ciarlet M, Mcdonald SM, et al. Uniformity of rotavirus strain nomenclature proposed by the rotavirus classification working group (RCWG). Arch Virol. 2011;156(8):1397-413. https://doi.org/10.1007/s00705011-1006-z.

5. Gong XH, Wu HY, Li J, et al. Epidemiology, aetiology and seasonality of infectious diarrhoea in adult outpatients through active surveillance in Shanghai, China, 2012-2016: a cross-sectional study. BMJ Open. 2018;8(9): e019699. https://doi.org/10.1136/bmjopen-2017-019699.

6. Yu J, Lai S, Geng Q, et al. Prevalence of rotavirus and rapid changes in circulating rotavirus strains among children with acute diarrhea in China, 2009-2015. J Inf Secur. 2019;78(1):66-74. https://doi.org/10.1016/j.jinf.2018.07. 004.

7. Sakpaisal P, Silapong S, Yowang A, et al. Prevalence and genotypic distribution of rotavirus in Thailand: a multicenter study. Am J Trop Med Hyg. 2019;100(5):1258-65. https://doi.org/10.4269/ajtmh.18-0763.

8. Kuang XZ, Xiao WJ, Teng Z, et al. Pathogenic characteristics of viral gastroenteritis among pediatric inpatients under five years old during 20142017. Zhonghua Liu Xing Bing Xue Za Zhi. 2019;40(8):895-9. https://doi.org/ 10.3760/cma.j.issn.0254-6450.2019.08.005.

9. Jonesteller $\mathrm{CL}$, Burnett $\mathrm{E}$, Yen $\mathrm{C}$, et al. Effectiveness of rotavirus vaccination: a systematic review of the first decade of global Postlicensure data, 20062016. Clin Infect Dis. 2017:65(5):840-50. https://doi.org/10.1093/cid/cix369.

10. Xue $Y$, Pan $\mathrm{H}$, et al. Epidemiology of norovirus infections among diarrhea outpatients in a diarrhea surveillance system in Shanghai, China: a crosssectional study. BMC Infect Dis. 2015;15(183).

11. Kuang X, Teng Z, Zhang X. Genotypic prevalence of norovirus GII in gastroenteritis outpatients in Shanghai from 2016 to 2018. Gut Pathog. 2019;11:40. https://doi.org/10.1186/s13099-019-0321-x.

12. Gouvea V, Glass RI, Woods $\mathrm{P}$, et al. Polymerase chain reaction amplification and typing of rotavirus nucleic acid from stool specimens. J Clin Microbiol. 1990;28(2):276-82.

13. Iturriza-Gomara M, Green J, Brown DW, et al. Diversity within the VP4 gene of rotavirus $P$ [8] strains: implications for reverse transcription-PCR genotyping. J Clin Microbiol. 2000;38(2):898-901.

14. Iturriza-Gomara M, Kang G, Gray J. Rotavirus genotyping: keeping up with an evolving population of human rotaviruses. J Clin Virol. 2004;31(4):259-65. https://doi.org/10.1016/j.jcv.2004.04.009.

15. Simmonds MK, Armah G, Asmah R, et al. New oligonucleotide primers for Ptyping of rotavirus strains: strategies for typing previously untypeable strains. J Clin Virol. 2008;42(4):368-73. https://doi.org/10.1016/j.jcv.2008.02.011.

16. Sequencher ${ }^{\oplus}$ DNA Sequence Analysis Software Gene Codes Corporation, Ann Arbor, Mi USA, http://www.genecodes.com. Accessed 9 Dec 2019.

17. Maes P, Matthijnssens J, Rahman M, et al. RotaC: a web-based tool for the complete genome classification of group a rotaviruses. BMC Microbiol. 2009; 9:238. https://doi.org/10.1186/1471-2180-9-238. 
18. Li W, Xiang W, Li C, et al. Molecular epidemiology of rotavirus a and adenovirus among children with acute diarrhea in Hangzhou, China. Gut Pathog. 2020;12:19. https://doi.org/10.1186/s13099-020-00359-4.

19. Tamura K, Stecher G, Peterson D, Filipski A, Kumar S. MEGA6: molecular evolutionary genetics analysis version 6.0. Mol Biol Evol. 2013;30:2725-9.

20. Kapikian AZ. Viral gastroenteritis. Jama. 1993;269(5):627-30.

21. Selvarajan S, Reju S, Pushpanathan P, et al. Molecular characterisation and clinical correlates of rotavirus in children and adults in a tertiary care Centre, Chennai, South India. Indian J Med Microbiol. 2017;35(2):221-7. https://doi. org/10.4103/ijmm.IJMM_16_51.

22. Zaraket $\mathrm{H}$, Charide $\mathrm{R}$, Kreidieh $\mathrm{K}$, et al. Update on the epidemiology of rotavirus in the Middle East and North Africa. Vaccine. 2017;35(45):6047-58.

23. Hallowell BD, Parashar UD, Curns A, et al. Trends in the laboratory detection of rotavirus before and after implementation of routine rotavirus vaccination - United States, 2000-2018. MMWR Morb Mortal Wkly Rep. 2019; 68(24):539-43. https://doi.org/10.15585/mmwr.mm6824a2.

24. Li D, Xu Z, Xie G, et al. Genotype of rotavirus vaccine strain LLR in China is G10P[15]. Bing Du Xue Bao. 2015;31(2):170-3.

25. Payne DC, Vinje J, Szilagyi PG, et al. Norovirus and medically attended gastroenteritis in U.S. children. N Engl J Med. 2013;368(12):1121-30. https:// doi.org/10.1056/NEJMsa1206589.

26. Fu C, Dong Z, Shen J, et al. Rotavirus gastroenteritis infection among children vaccinated and unvaccinated with rotavirus vaccine in southern China: a population-based assessment. JAMA Netw Open. 2018;1(4): e181382. https://doi.org/10.1001/jamanetworkopen.2018.1382.

27. Niewiesk S. Maternal antibodies: clinical significance, mechanism of interference with immune responses, and possible vaccination strategies. Front Immunol. 2014;5(446):446. https://doi.org/10.3389/fimmu.2014.00446.

28. Berlutti F, Pantanella F, Natalizi T, et al. Antiviral properties of lactoferrin--a natural immunity molecule. Molecules. 2011;16(8):6992-7018. https://doi. org/10.3390/molecules16086992.

29. Wang X. Y., Xu Z. Y., Von Seidlein L., et al., Incidence of diarrhea caused by rotavirus infections in rural Zhengding, China: prospective, populationbased surveillance. J Infect Dis, 2005. 192 Suppl 1(Supplement 1): p. S100S105,JJ], DOl: https://doi.org/10.1086/431507.

30. Sen A, Namsa ND, Feng N, et al. Rotavirus re-programs multiple IFN receptors and restricts their intestinal antiviral and inflammatory functions. $J$ Virol. 2020. https://doi.org/10.1128/jvi.01775-19.

31. Trubiano JA, Cairns KA, Evans JA, et al. The prevalence and impact of antimicrobial allergies and adverse drug reactions at an Australian tertiary Centre. BMC Infect Dis. 2015;15:572. https://doi.org/10.1186/s12879-015-1303-3.

32. Ye Q, Fu JF, Mao JH, et al. Haze is an important medium for the spread of rotavirus. Environ Pollut. 2016;216:324-31. https://doi.org/10.1016/j.envpol. 2016.05.090

33. Wang P, Goggins WB, Chan EYY. A time-series study of the association of rainfall, relative humidity and ambient temperature with hospitalizations for rotavirus and norovirus infection among children in Hong Kong. Sci Total Environ. 2018:643:414-22. https://doi.org/10.1016/j.scitotenv.2018.06.189.

34. Moe K, Shirley JA. The effects of relative humidity and temperature on the survival of human rotavirus in faeces. Arch Virol. 1982;72(3):179-86. https:// doi.org/10.1007/bf01348963.

35. Anderson EJ, Weber SG. Rotavirus infection in adults. Lancet Infect Dis. 2004; 4(2):91-9. https://doi.org/10.1016/s1473-3099(04)00928-4

36. Tian Y, Chughtai AA, Gao Z, et al. Prevalence and genotypes of group a rotavirus among outpatient children under five years old with diarrhea in Beijing, China, 2011-2016. BMC Infect Dis. 2018;18(1):497. https://doi.org/10. 1186/s12879-018-3411-3.

37. Zhou N, Lv D, Wang S, et al. Continuous detection and genetic diversity of human rotavirus a in sewage in eastern China, 2013-2014. Virol J. 2016;13(1): 153. https://doi.org/10.1186/s12985-016-0609-0.

38. Li JS, Cao B, Gao HC, et al. Faecal shedding of rotavirus vaccine in Chinese children after vaccination with Lanzhou lamb rotavirus vaccine. Sci Rep. 2018;8(1):1001. https://doi.org/10.1038/s41598-018-19469-w.

39. Matthijnssens J, Rahman M, Martella V, et al. Full genomic analysis of human rotavirus strain B4106 and lapine rotavirus strain 30/96 provides evidence for interspecies transmission. J Virol. 2006;80(8):3801-10. https:// doi.org/10.1128/jvi.80.8.3801-3810.2006.

\section{Publisher's Note}

Springer Nature remains neutral with regard to jurisdictional claims in published maps and institutional affiliations.

Ready to submit your research? Choose BMC and benefit from:

- fast, convenient online submission

- thorough peer review by experienced researchers in your field

- rapid publication on acceptance

- support for research data, including large and complex data types

- gold Open Access which fosters wider collaboration and increased citations

- maximum visibility for your research: over $100 \mathrm{M}$ website views per year

At BMC, research is always in progress.

Learn more biomedcentral.com/submissions 